\title{
SYSTEMIC SCLEROSIS-ASSOCIATED INTERSTITIAL LUNG DISEASE: A REVIEW OF THE LITERATURE
}

\author{
R. Dacheva, S. Monov \\ Clinic of Rheumatology, UMHAT "Sv. Ivan Rilski”, Medical University - Sofia
}

\begin{abstract}
Systemic sclerosis (SSc) is a connective tissue disease characterized by progressive sclerosis, affecting the skin and the internal organs, vasculopathy, and immune dysregulation. Interstitial pneumonias are a group of diffuse parenchymal lung diseases (DPLDs), or also called interstitial lung diseases (ILDs). ILD is a leading complication of SSc and a leading cause of mortality in patients with SSc. The pathogenesis of lung injury involves three major processes - persistent endothelial cell damage, immune system activation, and fibroblast activation leading to the accumulation of extracellular matrix and tissue damage. A comprehensive approach is required to properly diagnose and select appropriate therapy.
\end{abstract}

Key words: interstitial lung disease, systemic sclerosis, pulmonary fibrosis, antibodies

\section{INTRODUCTION}

Systemic sclerosis (SSc) is a chronic, systemic autoimmune connective tissue disease, which is characterized by skin and visceral involvement resulting from sclerotic changes and vasculopathy [ 1 , 2]. The origin of the term scleroderma comes from the Greek words "scleros" and "derma" and means thickened skin.

SSs has been divided into three subsets on the basis of the extent of skin involvement:

1) limited cutaneous scleroderma - skin involvement is limited to the distal parts of the limbs and face; it is characterized by the slow evolution of skin changes and the late appearance of visceral involvement; pulmonary arterial hypertension (PAH), biliary cirrhosis, telangiectasia and subcutaneous calcinosis are more common here.

2) diffuse cutaneous scleroderma - symmetrical thickening of the skin affecting the distal and proximal extremities, face and corpse, characterized by rapid progression of skin changes as well as early appearance of visceral involvement [3].

3) SSc sine scleroderma - absence of skin thickening but internal organ involvement.

Obliterative vasculopathy of the small arteries and fibrosis of target organs plays a key role in the pathogenesis of the disease. Vasculopathy consists of fibrointimal proliferation of small vessels and vasospastic episodes triggered by stress and cold leading to tissue ischemia [4].

A systematic analysis of the literature published on the topic in the scientific database was carried out. The following keywords were used: „systemic sclerosis“, „antibodies“, „interstitial lung disease“, „pulmonary fibrosis“.

\section{Pathogenesis}

The current concept of the pathogenesis of the disease is based on the triad: vasculopathy, inflammation associated with immune dysregulation leading to cellular activation and synthesis of nonspecific and specific autoantibodies, and excessive collagen synthesis leading to marked fibrosis of the skin and internal organs.

SSc occurs in two stages: early (inflammatory phase) and late (fibrotic) [5].

Vascular dysfunction is thought to be the earliest change and initiating step in the pathogenesis of the disease. Endothelial damage is the result of an attack of proinflammatory cytokines produced by activated lymphocytes, as well as the presence of antibodies against endothelial cell antibodies (AECA). Data exists that AECAs lead to endothelial cell apoptosis [6].

In addition to AECA production, activated $B$ lymphocytes also synthesize a number of other autoantibodies. T-cell activation leads to the synthesis of lymphokines that stimulate fibroblasts for increased collagen production. Fibroblasts secrete a number of cytokines and chemokines, enhancing the expression of adhesion molecules such as ICAM-1 (intracellular adhesion molecule-1) and the production of growth factors such as TGF $\beta$ (transforming growth factor beta) and CTGF (connective tissue growth factor)). CTGF and TGF $\beta / S m a d$ signaling pathways are responsible for increased collagen production by skin fibroblasts [5]. 


\section{DifFuse PARENCHYMAL LUNG DISEASES}

Interstitial pneumonias are a group of diffuse parenchymal lung diseases (DPLDs), or also called interstitial lung diseases (ILDs). They are a heterogeneous group of diseases (Figure 1) characterized by inflammation and / or fibrosis of the lung parenchyma, leading to impaired gas exchange, respiratory distress and even death [5]. The primary site of injury is the pulmonary interstitium. It includes the space between the epithelial and endothelial basement membranes and contains connective tissue matrix, fibroblasts and macrophages. In 2013, The American Thoracic Society and the European Respiratory Society (ATS/ ERS) revised the previous classification of DPLDs, dividing them into 4 main groups (Figure 1) [7, 8].

The major idiopathic interstitial pneumonias (IIPs) are subdivided into 4 groups:

- chronic fibrosing - idiopathic pulmonary fibrosis (idiopathic pulmonary fibrosis, IPF) and nonspecific interstitial pneumonia (NSIP)

- smoking related - desquamative interstitial pneumonia (DIP) and respiratory bronchiolitis (re- spiratory bronchiolitis - associated interstitial lung disease, RB-ILD)

- acute/subacute - cryptogenic organizing pneumonia (COP) and acute interstitial pneumonia (AIP).

- rare - lymphoid interstitial pneumonia (LIP) and idiopathic pleuroparenchymal fibroelastosis (PPFE) $[9,10]$.

\section{Pathogenesis of SSC-Associated INTERSTITIAL LUNG DISEASE (SSC-ILD)}

Pulmonary involvement in SSc may include interstitial lung disease, pneumonitis, and pulmonary hypertension to varying degrees [4]. ILD is a leading complication of SSc, and together with pulmonary arterial hypertension (PAH), is a leading cause of mortality in patients with SSc [11].

The pathogenesis of SSC-ILD is not fully understood. Three major processes are assumed to be involved in the pathogenesis of lung disease: 1) persistent and recurrent damage of endothelial cellsm 2) immune system activation and 3) fibroblast activation leading to extracellular matrix accumulation and tissue damage.

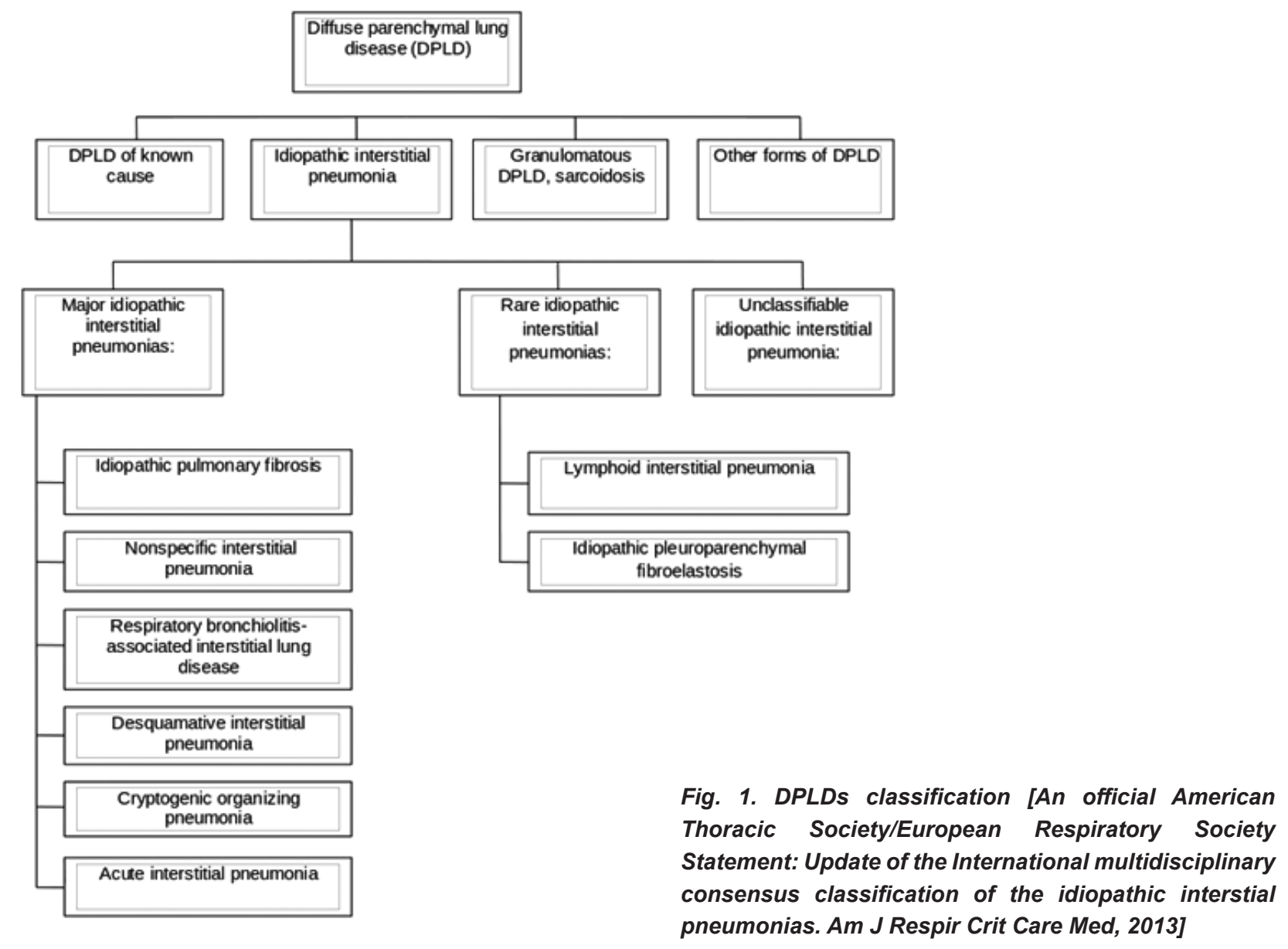


The cells that play an essential role in the pro-fibrotic process are myofibroblasts, alveolar epithelial cells, fibroblasts, endothelial cells. The key role in fibroblast activation is played by TGFb, which is secreted by activated lymphocytes, monocytes, T-cells or fibroblasts. The binding of TGFb to its receptors activates the Smad signaling pathways. The targets of Smad-dependent TGFb signaling are collagen type I, plasminogen activator inhibitor and CTGF. Under normal conditions, fibroblasts are responsible for the functional and structural integrity of connective tissue in the parenchymal organs. Upon activation by TGF $\beta$, fibroblasts proliferate, migrate, secrete growth factors and cytokines and differentiate into myofibroblasts. This fibroblast response promotes effective repair in tissue damage. Under physiological conditions, the process is self-limiting and ends with the repair of the damaged tissue. Under pathological conditions, fibroblast activation persists, leading to increased remodeling of the extracellular matrix [12].

Toll-like 4 receptors (TLR4) are also involved in the pathogenesis of fibrosis. They can be activated by cellular damage, autoimmune processes and oxidative stress. In cutaneous and pulmonary biopsy taken from patients with SSc, increased expression of TLR4 was detected, which in turn potentiated TGFb signaling and supresses antifibrotic microRNAs [13, 14]. Antitopoisomerase - I antibodies form immune complexes and activate TLRs in immune cells. This results in the release of interferon (IFN), which in turn induces the expression of TLR3 on the surface of fibroblasts. Profibrotic response is activated [15].

In ILD, inflammatory cells (lymphocytes, monocytes, macrophages) are known to infiltrate the lung parenchyma and produce pro-inflammatory and profibrotic mediators, including IL-4, IL-13, TGFb, chemokines. Fibroblasts proliferate and produce an increased amount of connective tissue.

The differentiation between connective tissue disease-associated ILD (CTD-ILD) and idiopathic interstitial pneumonia (IIP), in which the cause of the disease remains unknown, is crucial for the prognosis and the therapeutic approach [16, 17, 18].

\section{DiAgNOSTIC APPROACH}

The incidence of SSc-ILD varies according to the diagnostic methodology used. Functional pulmonary tests and high resolution computed tomography (HRCT) remain the gold standard for diagnosing pulmonary abnormalities. Interstitial abnormalities are evident on HRCT in up to $80 \%$ of SSc patients, but only $30-40 \%$ ot patients develop clinically significant ILD [19].

Some demographic, clinical, and immunological parameters are associated with pulmonary involvement in SSc: such as male sex, higher modified Rodnan skin scor (mRSS), presence of cardiac involvement, increased levels of creatine phosphokinase, antitopoisomerase antibodies and absence of anticentromere antibodies [20, 21].

Diffuse interstitial lung disease is a common manifestation of systemic connective tissue diseases, with histological and radiographic findings corresponding with their idiopathic forms [22].

According to the EULAR scleroderma trials and research (EUSTAR) database, 35\% of mortality rates between 2004 and 2008 in SSc are related to pulmonary fibrosis [23].

According to the criteria of N. Goh et al. (Fig. 2) patients with HRCT extent of lung disease > $20 \%$ of the lung and those whose HRCT showed fibrosis between $10-20 \%$ with a FVC $<70 \%$ predicted are considered as having severe lung disease [5, 24].

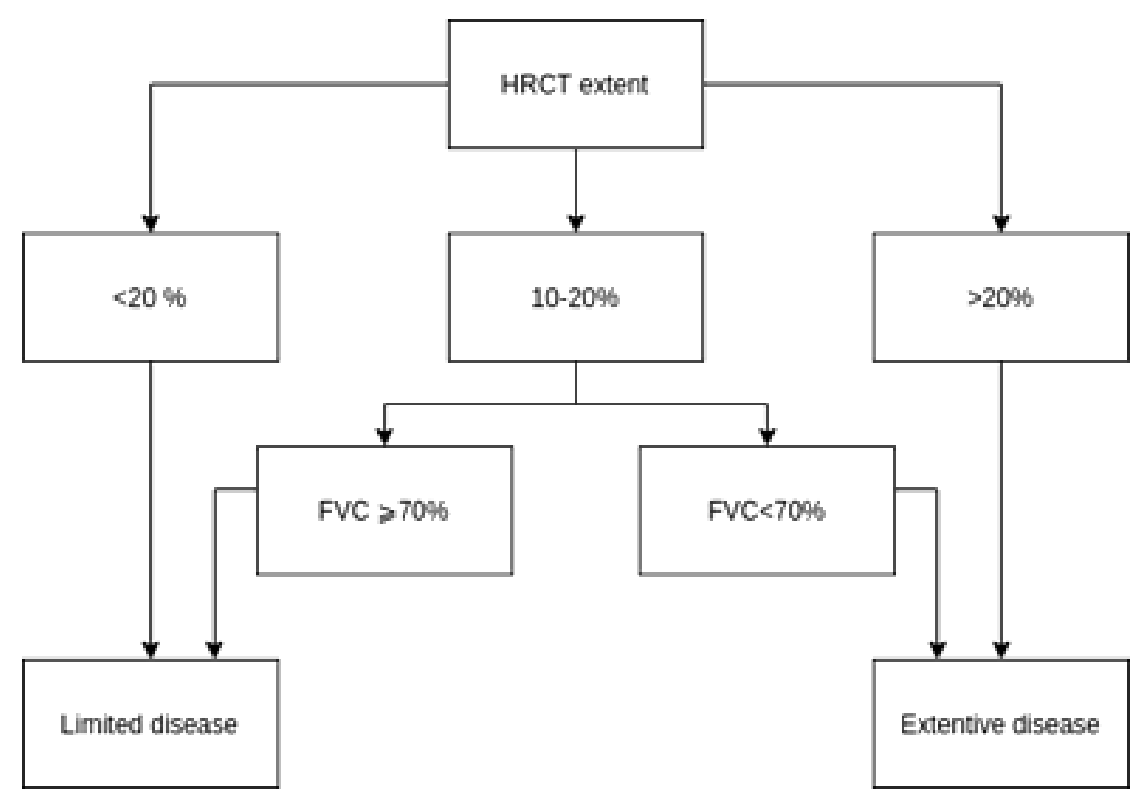

Definition of abbreviation: HRCT - high-resolution computed tomography, FVC - forced vital capacity

Fig. 2. Assessment of severity of SSc-ILD (adapted from Goh, 2008 [23]) 


\section{Clinical and radiological features}

Patients with connective tissue diseases-associated ILD (CTD-ILD) have a better prognosis than patients with idiopathic interstitial pneumonia [25, 26]. A leading symptom of pulmonary involvement in SSc is dyspnea initially on exertion which may persist at rest, depending on the severity of the involvement.

The most common type of interstitial lung disease (Table 1) found in patients with systemic connective tissue disease, including SSc-ILD, is nonspecific interstitial pneumonia (NSIP), 56-78\% [7, $27,28]$. The better prognosis for CTD-ILD compared to the idiopathic forms is due to this fact.

In 1994, A. Katzenstein and R. Fiorelli introduced the term "non-specific interstitial pneumonia“. According to the severity of inflammation and/or fibrosis in lung biopsies, the authors divided NSIP into three main subtypes: 1) predominantly interstitial inflammation, 2) with both inflammation and fibrosis, 3) predominantly fibrosis [29]. The median age of patients with NSIP is between 40 and 50 years. The beginning is usually gradual. The clinical picture is presented by shortness of breath, cough, constitutional manifestations - increased fatigue and weight loss. Fever is less commonly observed. Auscultatory findings are usually represented by wheezing and crackles which are initially predominantly basal. Functional pulmonary tests reveal a restrictive ventilatory defect [7].

It is of great importance to differentiate NSIP from other interstitial lung diseases, including usual interstitial pneumonia (UIP) and hypersensitive pneumonitis, due to differences in treatment and prognosis. NSIP is characterized by homogeneous diffuse infiltrates in the lung parenchyma. The interstitium can

Table 1. Radiological pattern of NSIP and UIP

\begin{tabular}{|l|l|l|}
\hline \multicolumn{2}{|c|}{ Radiological features of NSIP and UIP } \\
\hline NSIP Classification type & \multicolumn{1}{|c|}{ Distribution } & \multicolumn{1}{c|}{ HRCT pattern } \\
& Basal, \\
& Peripheral/subpleural, & $\begin{array}{l}\text { Ground-glass opacities } \\
\text { Reticulation } \\
\text { Subpleural sparing }\end{array}$ \\
& Symmetrical & Honeycombing \\
& Peripheral & Reticulation \\
& Subpleural & Traction bronchiectasis \\
& Bronchiolectasis \\
& Basal predominance \\
& Temporal heterogeneity & Centrilobular sparing \\
\hline
\end{tabular}

Definition ot abbreviation: NSIP - nonspecific interstitial pneumonia, UIP - usual interstitial pneumonia
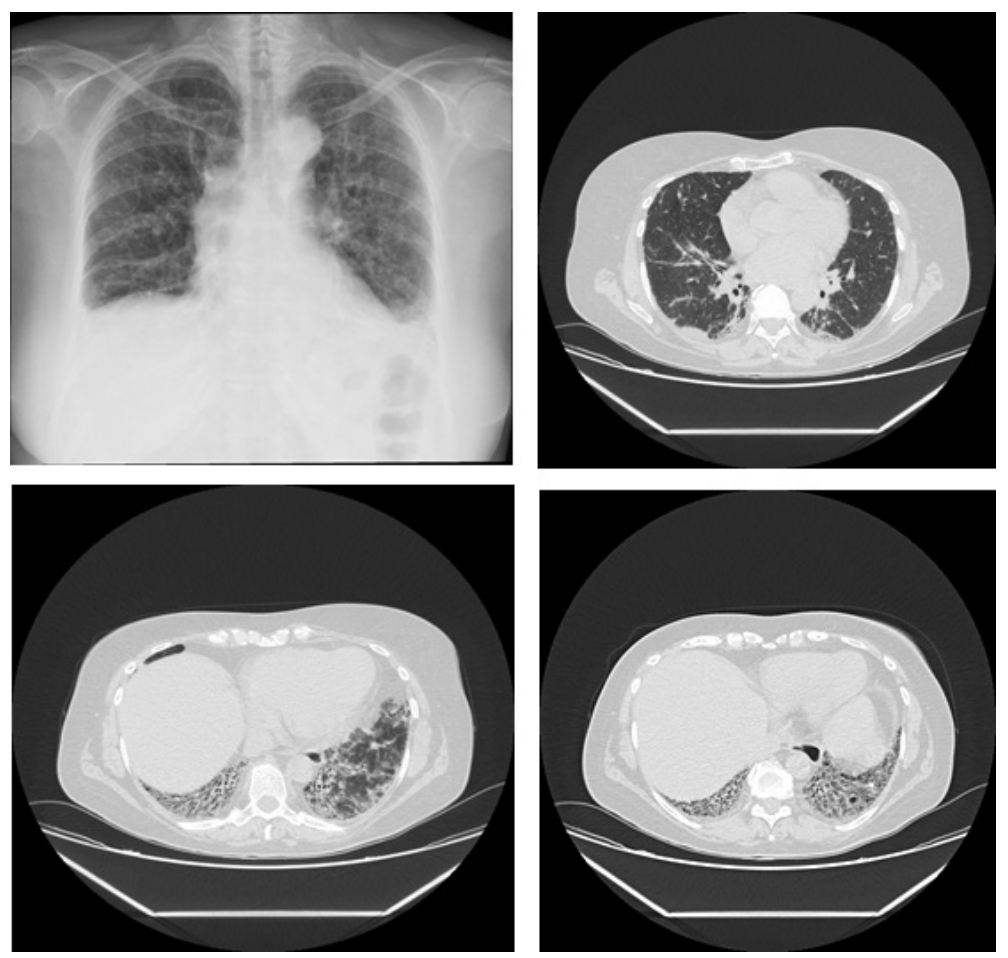

Fig. 3. Conventional radiography and HRCT of a SSC-ILD patient 
be thickened by inflammatory cell infiltrates, fibrosis, or both. Usually, the alveolar structure is preserved. Radiographic findings include ground-glass opacities, with predominantly basal and subpleural distribution. Reticular shading and traction bronchiectasis can also be seen. Subpleural sparing is suggestive for NSIP [22]. The changes are usually bilateral and symmetrical. Honeycomb changes are more characteristic of usual interstitial pneumonia and are most commonly absent in NSIP. [30] In the case of longterm involvement, SSc-ILD may be associated with traction bronchiectasis and fibrotic changes [31].

In rarer cases, UIP is observed. The histologic feature includes areas of normal parenchyma, alternating with areas at different stages of inflammation, fibrosis, and honeycombing pattern. This "temporal heterogeneity" is a characteristic feature of UIP and differentiates it from NSIP. The lesions are predominantly basal and subpleural. The radiographic image is typically similar to that of the fibrotic form of NSIP with traction bronchiectasis and bronchiolectasis. The absence of honeycombing makes UIP unlikely [22].

In isolated cases, diffuse alveolar damage or organizing pneumonia is observed.

\section{Autoantibodies AND SSC-ILD}

Different antibodies are associated with different characteristics of pulmonary involvement. Anti-topoisomerase I antibodies (anti-Scl-70) are associated with the presence of pulmonary fibrosis, while anticentromere antibodies (ACA) are associated with $\mathrm{PAH}$ and rarely correlate with interstitial lung involvement. Nucleolar antibodies, anti-U3 RNP, and anti-TH/To are associated with an increased risk of developing pulmonary hypertension. The presence of anti-RNA polymerase III antibodies has been associated with the development of marked cutaneous sclerosis and an increased incidence of renal crises. Severe ILD is rarely observed in these patients [32].

There is still controversy as to whether autoantibodies in systemic sclerosis have a pathogenetic role or are an epiphenomenon of the disease process. ACA are rarely detected in healthy individuals, and rarely positive in patients with other CTDs [33, $34,35]$. In some studies, the presence of ACA has been associated with a decreased incidence of interstitial pulmonary fibrosis [36, 37, 38, 39].

The incidence of anti-Scl-70 antibodies in patients with SSc and pulmonary fibrosis is about $45 \%$. ACA and anti-Scl-70 antibodies occur simultaneously in patients with SSc $<0.5 \%$, which makes them mutually exclusive $[40,41,42]$. They correlate with the degree of radiographic involvement [43].

\section{THERAPEUTIC APPROACH}

Immunosuppressive therapy remains the mainstay of treatment of SSc-ILD. However, advances in understanding the pathogenesis of lung injury has led to progress in the development of targeted therapies. Active treatment is recommended for patients with rapid disease progression, verified by a decrease in functional pulmonary tests, progression of pulmonary fibrosis, and / or worsening of the clinical course $[44,45,46]$. Therapeutic options include cyclophosphamide (CYC), mycophenolate mofetil (MMF), azathioprine, rituximab, antifibrotic therapies. MMF is an inhibitor of lymphocytic proliferation and is often used as first-line therapy in patients with SSc-ILD. According to the results of Scleroderma Lung Study II, MMF at a dose of $3 \mathrm{~g} /$ day for 2 years as the first choice of immunosuppressive therapy is as effective as oral CYC for one year, followed by placebo for another year [47].

Rituximab, a monoclonal antibody targeting CD20 positive $B$ lymphocytes, has been used in SSc-ILD refractory to standard therapy $[15,48]$.

Antifibrotic therapy includes nintedanib and pirfenidone. They have antiproliferative effects and are approved for use in idiopathic pulmonary fibrosis. Scleroderma Lung Study III is a double-blind, parallel, randomized, placebo-controlled clinical trial in patients with SSc-ILD. It aims to evaluate the efficacy and safety of MMF and pirfenidone [49].

Nintedanib inhibits the proliferation, migration and differentiation of fibroblasts and the production of extracellular matrix $[50,51,52]$. In the SENSCIS trial, 580 patients with SSc-ILD affecting at least $10 \%$ of the lungs were randomly assigned to receive $250 \mathrm{mg}$ Nintedanib twice per day or placebo for 52 weeks. During 52 weeks, the number of patients with decline in FVC of more than $5 \%$ or more than $10 \%$ was lower in the nintedanib group. As of September 2019 nintedanib became FDA-approved therapy for SSc-ILD [53].

Randomized studies comparing CYC therapy and autologous stem cell transplantation (ASCT) have shown stabilization of lung function and improvement of skin sclerosis in SSc patients [54]. EULAR recommends ASCT in patients with progressive SSc at risk of organ failure [55].

Patients who do not respond to standard therapy and without contraindications are indicated for lung transplantation.

\section{Conclusion}

Interstitial lung disease is a leading complication in patients with SSc and a leading cause of mortality. 
Improved understanding of the pathogenesis of the disease has led to advances in SSc-ILD treatment. A comprehensive approach is needed to make the right diagnosis and to choose the appropriate therapy.

\section{Библиография / References:}

1. Abraham DJ, Varga J. 2005. Scleroderma: from cell and molecular mechanism to disease model. Trends Immunol. 26:587-595.

2. Bijlsma JW, Da Silva JAP, Hachulla E et al., Textbook on rheumatic diseases, 2012, 546-567.

3. Abraham, DJ, T. Krieg, J. Distler et al. Overview of pathogenesis of systemic sclerosis, Rheumatology Oxford, 2009; 48, Suppl. 3: iii3-7.

4. Katsumoto TR, Whitfield ML, Connolly MK, The pathogenesis of systemic sclerosis, Annu Rev Pathol, 2011, 6:509-37.

5. Hachulla E, Czirjak L. Textbook on Systemic Sclerosis, EULAR 2013, 53-59.

6. Bordon A., Dueymes M., Levy Y. The binding of some human antiendothelial cell antibodies induces endothelial cell apoptosis, J. Clin Invest, 1998 May 15, 101(10): 2029-2035.

7. American Thoracic Society/European Respiratory Society. International multidisciplinary consensus classification of idiopathic interstitial pneumonias, Am J Respir Crit Care Med 2002; 165 (2) 277-304.

8. An official American Thoracic Society/European Respiratory Society Statement: Update of the International multidisciplinary consensus classification of the idiopathic interstial pneumonias. Am J Respir Crit Care Med 2013; 188 (6): 733748.

9. Antoniou KM, Margaritopoulos GA, Tomassetti S et al. Interstitial lung disease, European Respiratory Review 2014 23:40-54

10. Oliveira DS, De Arimatela Araujo Filho J, Fernando Lins Paica A et al. Idiopathic interstitial pneumonias: review of the latest American Thoracic Society/European Respiratory Society classification, Radiol Bras 2018, Sep-Oct; 51(5): 321-327.

11. Steen VD, Medsger TA. Changes in causes of death in systemic sclerosis, 1972-2002. Ann Rheum Dis. 2007; 66(7):940-944.

12. Honda, N., M. Jinnin, I. Kajihara et al., TGF-beta-mediated downregulation ot microRNA-196a contributes to the constitutive upregulated type I collagen expression in scleroderma dermal fibroblasts. J Immunol 2012; 188:3323-3331.

13. Cappelli S, Randone SB, Camiciottoli G et al. Interstitial Lung Disease in Systemiv Sclerosis: where do we stand, European Respiratory Review, 2015, 24:411-419.

14. Varga J, Abraham D. Systemic sclerosis: a prototypic multisystem fibrotic disorder, The Journal of Clinical Investigation, 117, 557-567.

15. Mirsaeidi M, Barletta P, Glassberg M K. Systemic Sclerosis Associated Interstitial Lung Disease: New Direction in Disease Management, Frontiers in Medicine (Lausanne), 2019:6:248

16. Park JH, Kim DS, Park IN et al. Prognosis of fibrotic interstitial pneumonia: idiopathic versus collagen vascular disease-related subtypes, Am J Respir Crit Care Med, 2007 Apr 1; 175 (7): 705-11.

17. Raghu G, Collard HR, Egan JJ et al. An official ATS/ERS/ JRS/ALAT Statement: Idiopathic Pulmonary Fibrosis: Evi- dence-based Guidelines for Diagnosis and Management, Am J Respir Crit Care Med, 2011;15; 186(6): 788-824.

18. Solomon JJ, Chartrand S, Fischer A. Current approach to connective tissue disease-associated interstitial lung disease, Curr Opin Pulm Med, 2014 Sep 20(5): 449-56.

19. Perelas A, Silver RM, Arrossi AV et al. Systemic sclerosis-associated interstitial lung dissease, Lancet Respir Med 2020,8(3), 304-320, https://doi.org/10.1016/S22132600(19)30480-1

20. Steen VD, Owens GR, Fino GJ et al. Pulmonary Involvement in systemic sclerosis (scleroderma). Arthritis Rheum, 1985;28(7):759-67.

21. Assassi S, Sharif R, Lasky RE et al. Predictors of interstitial lung disease in early systemic sclerosis: a prospective longitudinal study of the GENISOS cohort. Arthritis Res Ther 12, R166 (2010) https://doi.org/10.1186/ar3125

22. Ysamat Marfa R, Benito Ysamat A, Espejo Perez S, et al. Lung disease associated with connective tissue disease. Radiology 2013;55:107-117.

23. Tyndall AJ, Bannert B, Vonk M, et al. Causes and risk factors for death in systemic sclerosis: a study from the EULAR scleroderma trials and research (EUSTAR) database. Ann Rheum Dis. 2010; 69:1809-15.

24. Goh NS, Desai SR, Veeraraghavan S, et al. Interstitial lung disease in systemic sclerosis: a simple staging system, American Journal of Respiratory and Critical Care Medicine, 2008; 177(11); 1248-54.

25. Hwang J-H, Misumi S, Sahin H et al. Computed Tomographic Features of Idiopatic Fibrosing Interstitial Pneumonia: Comparison With Pulmonary Fibrosis Related to Collagen Vascular Disease; Journal of Computer Asisted Tomography. 33(3):410-415.

26. Park JH, Kim DS, Park I-N et al. Prognosis of Fibrotic Interstitial Pneumonia, American Journal of Respiratory and Critical Care Medicinie, 175(7).

27. Kim EA, Lee KS, Johkoh T, et al. Interstitial lung diseases associated with collagen vascular diseases: radiologic and histopathologic findings, Radiographics, 2003;23(5):1340.

28. Fujita J, Yoshinouchi T, Ohtsuki Y. Non-specific interstitial pneumonia as pulmonary involvement of systemic sclerosis, Ann Rheum Dis 2001; 60:281-28.

29. Katznestein AL, Fiorelli RF. Nonspecific interstitial pneumonia/fibrosis: histologic features and clinical significance, Am J Surg Pathol, 1994;18:136-147.

30. Kligerman SJ, Groshong S, Brown KK et al. Nonspecific Interstitial Pneumonia: Radiologic, Clinical, and Parhologic Consideration, 2009,29(1).

31. Solomon JJ, Olson AL, Fischer A. et al. Scleroderma lung disease, Eur Respir Rev, 2013;22(127):6-19.

32. Steen, VD. Autoantibodies in Systemic Sclerosis, Seminars in Arthritis and Rhematism, 2005, 35(1), 35-42.

33. Vasquez-Abad D, Wallace S, Senecal JL et al. Anticentromere autoantibodies. Evaluation of an ELISA using recombinant fusion protein CENT-B as antigen, Arhtritis Rheum., 1994;37:248-252.

34. Sato S, Fujimoto M, Inh $\mathrm{H}$ et al. Antibodies to centromere and centriole in scleroderma spectrum disorders, Dermatology, 1994; 189:23-26.

35. Clegg DO, Williams HJ, Singer JZ et al. Early undifferentiated connective tissue disease. II. The frequency of circulation antinuclear antibodies in patients with early rheumatic disease, J Rheumatol., 1991;18:1340-26. 
36. Kane GC, Varga J, Conant EF, et al. Lung involvement in systemic sclerosis (scleroderma): relation to classification based on extent of skin involvement or autoantibody status, Respir Med, 1996; 90(4): 223-30.

37. Steen VD, Powell DL, Medsger TA Jr. Clinical correlations and prognosis based on serum autoantibodies in patients with progressive systemic sclerosis. Arthritis Rheum. 1988; 31:196-203.

38. Arnett FC, Reveille JD, Goldstein R et al. Autoantibodies to fibrillarin in systemic sclerosis (scleroderma): an immunogenetic, serologic and clinical analysis. Arthritis Rheum. 1996;39:1151-1160.

39. Kuwana M, Kaburaki J, Okano Y, et al. Clinical and prognostic associations based on serum antinuclear antibodies in Japanese patients with systemic sclerosis, Arhtritis Rheum. 1994;37:75-83.

40. Reveille JD, Solomon DH, American College of Rheumatology, Ad Hoc Committee on Immunological Testing Guidelines Evidence-based guidelines for the use of fimmunologic laboratory tests: anti-centromere, Scl-70 and nucleolar antibodies. Arthritis Rheum. 2003;49(3):399-412.

41. Spencet-Green G, Alter D, Welch HG. Test performance in systemic sclerosis: anti-centromere and anti-Scl-70 antibodies. Am J Med. 1998;103:242-248.

42. Ferri C, Valentini G, Cozzi F, et al. Systemic sclerosis: demographic, clinical, and serologic features and survival in 1,012 Italian patients. Medicine. 2002; 81:139-153.

43. Riboldi $P$, Asero R, Origgi $L$ et al. Antinuclear antibodies in progressive systemic sclerosis. Clin Exp Rheum. 1985;3:205-211.

44. Silver KC, Silver RM. Management of systemic-sclerosis-associated interstitial lung disease. Rheum Dis Clin N Am. 2015; 41:439-57.

45. Denton CP, Khanna D. Systemic sclerosis. Lancet 2017; 390(10103): 1685-1699.

46. Vincent-Cottin, Kevin K, Brown, Interstitial lung disease associated with systemic sclerosis (SSc-ILD), Respir Res 20, 13(2019). https://doi.org/10.1186/s12931-019-0980-7
47. Tashin DP, Roth MD, Clements PJ et al. Mycophenolate mofetil versus oral cyclophosphamide in scleroderma-related interstitial lung disease (SLS II): a randomised controlled, double-blind, parallel group trial. Lancet Respir Med 2016; 4:708-19.

48. Daoussis D, Liossis SN, Tsamandas AC et al. Effect of longterm treatment with rituximab on pulmonary function and skin fibrosis in patients with diffuse systemic sclerosis. Clin Exp Rheumatol. (2012) 30 (2 suppl.71): S17-22.

49. Roth M. Scleroderma Lung Study III - Combining Pirfenidone With Mycophenolate (SLSIII). https://clinicaltrials.gov/ ct2/show/NCT03221257

50. Huang J. Beyer, Palumbo-Zerr K, Zhang Y. et al. Nintedanib inhibits fibroblast activation and ameliorates fibrosis in preclinical models of systemic sclerosis. Ann Rheum Dis. 2016; 75:883-90.

51. Huang J, Maier C, Zhang $Y$ et al. Nintedanib inhibits macrophage activation and ameliorates vascular and fibrotic manifestations in the Fra2 mouse model of systemic sclerosis. Ann Rheum Dis. 2017;76:1941-8.

52. Wollin L, Maillet I, Quesniaux V et al. Antifibrotic and anti-inflammatory activity of the tyrosine kinase inhibitor nintedanib in experimental models of lung fibrosis. J Pharmacol Exp Ther. 2014; 349:209-20.

53. Distler O, Highland KB, Gahlemann M, et al. Nintedanib for systemic sclerosis-associated interstitial lung disease. N Engl J Med 2019; 380:2518-28.

54. Burt RK, Shah SJ, Dill K et al. Autologous non-myeloablative haemopoetic stem-cell transplantation compared with pulse cyclophosphamide once per month for systemic sclerosis (ASSIST): an open-label, randomised phase 2 trial. Lancet. 2011; 378:498-506.

55. Kowal Bielecka O, Fransen J, Avouac J, et al. Update of EULAR recommendations for the treatment of systemic sclerosis. Ann Rheum Dis 2017; 76: 1327-39.

Submitted: 06.07.2020

Постъпил за печат: 06.07.2020 2.

Адрес за кореспонденция:

Д-р Росица Светославова Дачева

ул. Урвич 13

тел: 0887828079

rdacheva@gmail.com $\triangle$ Correspondence address:

Rositsa Svetoslavova Dacheva, MD

13 Urvich str,

tel: 0887828079

rdacheva@gmail.com 